\title{
EVOLUÇÃO DO TRANSPLANTE RENAL APÓS SUSPENSÃO DA AZATIOPRINA EM PACIENTES ESTÁVEIS COM IMUNOSSUPRESSÃO TRÍPLICE
}

\author{
Progression of renal transplant following removal of azathioprine \\ in stable triple immunosuppressed patients
}

\begin{abstract}
Euler Pace Lasmar ${ }^{1}$, Augusto Cesar Santos Junior ${ }^{2}$, Rafael Lage Madeira ${ }^{2}$, José de Resende Barros Neto ${ }^{2}$, Leonardo Faria Lasmar ${ }^{4}$, Julienne Borges Fuji ${ }^{4}$, Marcus Faria Lasmar ${ }^{5}$
\end{abstract}

\section{RESUMO}

Introdução: Até 1997, a imunossupressão clássica era tríplice, constituída pela associação da ciclosporina, azatioprina e prednisona. Entretanto, em alguns casos, a azatioprina era retirada devido a reações colaterais importantes. Objetivo: Comparar a evolução de pacientes transplantados renais, em que a azatioprina foi retirada do esquema imunossupressor de base inicial, com ciclosporina, azatioprina e prednisona, a pacientes que mantiveram a imunossupressão. Método: Estudo, retrospectivo e observacional. Foram avaliados trinta e quatro pacientes submetidos a primeiro transplante que apresentavam as mesmas características, divididos em dois grupos: no grupo 1, com dezessete pacientes, a azatioprina foi suspensa, e, no grupo 2, foi mantida e associada à ciclosporina e à prednisona. Resultados: A função renal, incidência de proteinúria, hipertensão arterial, dislipidemia, infecções e outras complicações foram semelhantes em ambos os grupos. Conclusão: A retirada da azatioprina do esquema de imunossupressão inicial, com ciclosporina e prednisona, em pacientes com mais de três meses de transplante, não determinou complicações importantes na evolução do enxerto.

Descritores: Azatioprina, Transplante, Evolução, Suspensão e Imunossupressão.

Trabalho realizado na Faculdade de Ciências Médicas - Hospital Mater Dei - Unidade de Transplante Renal - Belo Horizonte - MG.

1. Professor Titular de Nefrologia da Faculdade de Ciências Médicas de Minas Gerais, Coordenador do Serviço de Nefrologia e Transplante Renal do Hospital Mater Dei;

2. Médico Residente em Nefrologia do Hospital Felício Rocho;

3. Acadêmico de Medicina da Faculdade de Ciências Médicas de Minas Gerais;

4. Professora de Estatística da UNILESTE;

5. Médico Assistente da Disciplina de Clínica Médica da Faculdade Paulista de Medicina UNIFESP;

Endereço para correspondência: Euler Pace Lasmar - Rua Newton, 89 - Santa Lúcia CEP: 30360-200 - Belo Horizonte - MG - Fone/Fax: (31) 3295-5000 - E-mail: lasmar@superig.com.br

Recebido em: 31.01.2005

Aceito em: 01.03.2005

\section{INTRODUÇÃO}

Desde a introdução da ciclosporina como droga imunossupressora, a sobrevida do enxerto renal melhorou consideravelmente. ${ }^{1,2,3} \mathrm{~A}$ imunossupressão tríplice com ciclosporina (CsA), azatioprina (AZA) e prednisona (PRED) foi iniciada em transplante renal (Tx) em $1987^{4,5}$ com a finalidade de reduzir a dose e os efeitos colaterais da ciclosporina. Os resultados da associação desses imunossupressores resultou na melhora substancial da sobrevida do enxerto. ${ }^{6,7}$ Entretanto, a AZA pode determinar reações colaterais importantes, ${ }^{8}$ sendo necessária sua suspensão ou substituição por outra droga imunossupressora, como o micofenolato mofetil ou o sódico e o sirolimo.

\section{OBJETIVO}

O objetivo deste trabalho foi avaliar a função renal do enxerto (desfecho primário) e a ocorrência de outras complicações (desfecho secundário) em pacientes transplantados renais estáveis (mais de três meses de Tx), com seguimento de dois anos, após a retirada da AZA do esquema imunossupressor de base inicial, com CsA, AZA, PRED.

\section{MATERIAL E MÉTODO}

Estudo tipo coorte, retrospectivo e observacional. Foram avaliados trinta e quatro pacientes, com, no mínimo, três meses do primeiro Tx, sem proteinúria no exame de urina, no período de 1992 a 1995 , divididos em dois grupos. No grupo $1(\mathrm{n}=17)$, a AZA foi retirada do esquema imunossupressor devido à necessidade de tratamento 
de gota grave (41,2\%), anemia importante $(17,7 \%)$, hepatotoxicidade $(17,7 \%)$, pancreatite $(11,8 \%)$ e hepatite $\mathrm{B}$ ou C $(11,8 \%)$. No grupo 2 $(\mathrm{n}=17)$, o esquema tríplice foi mantido. O pareamento foi realizado observando-se a idade, o sexo, a data do transplante e o tipo de doador. A imunossupressão inicial com CsA foi feita na dose de 8 a $10 \mathrm{mg} / \mathrm{kg}$ dia, a fim de se manter o through level entre 250 a $400 \mathrm{ng} / \mathrm{ml}$ (TDX monoclonal, Abbott) nos seis primeiros meses e 100 a $200 \mathrm{ng} / \mathrm{ml}$ após esse período. A AZA foi utilizada na dose de $2 \mathrm{mg} / \mathrm{kg} / \mathrm{dia}$ e a PRED na dose de carga de $1 \mathrm{mg} / \mathrm{kg}$; a seguir, reduzida para $0,5 \mathrm{mg} / \mathrm{kg} /$ dia e, progressivamente, $0,1 \mathrm{mg} / \mathrm{kg} / \mathrm{dia}$, semanalmente, até o terceiro mês. Em seguida 5,0 a 7,5 $\mathrm{mg}$ por dia. Os grupos não apresentaram diferenças estaticamente significativas quanto às variáveis demográficas e laboratoriais (Tabela 1). A doença de base é mostrada na Tabela 2. A função renal foi estimada pela fórmula de Cockroft-Gault e os resultados foram expressos por média desvio padrão. $O$ teste $t$ de Student foi utilizado para análise estatística. A significância foi estipulada para $\mathrm{p}<0,05$.

Tabela 1 - Características demográficas e laboratoriais dos pacientes

\begin{tabular}{|c|c|c|c|}
\hline Variável & Grupo 1 & Grupo 2 & Valor $p$ \\
\hline Idade (média em anos) & $38,2 \pm 10,1$ & $34,9 \pm 7,0$ & 0,31 \\
\hline $\operatorname{Sexo}(M / F)$ & $12 / 05$ & $12 / 05$ & -- \\
\hline Raça $(B / M / N)$ & $11 / 04 / 02$ & $12 / 05 / 00$ & -- \\
\hline \multicolumn{4}{|l|}{ Tempo de suspensão da } \\
\hline AZA (média em meses) & $61,8 \pm 34,5$ & $61,1 \pm 34,5$ & 0,69 \\
\hline Doador (DVR/Cad) & $14 / 3$ & $14 / 3$ & -- \\
\hline Dose da CsA (média antes) & $268,7 \pm 121,5^{\star}$ & $200,2 \pm 156,7^{*}$ & 0,14 \\
\hline Dose da CsA (média após) & $384,1 \pm 316,3^{*}$ & $530,0 \pm 436,0^{*}$ & 0,14 \\
\hline Dose de AZA (média antes) & $102,5 \pm 45,4^{*}$ & $105,8 \pm 40,4^{*}$ & 0,38 \\
\hline Dose de AZA (média após) & ---- & $108,7 \pm 39,5^{*}$ & 0,001 \\
\hline Dose de PRED (média & & * & \\
\hline antes) & $8,7 \pm 4,3^{*}$ & $7, \pm 2,2$ & 0,12 \\
\hline Dose de PRED (média após) & $7,1 \pm 1,3^{*}$ & $6,9 \pm 1,1^{*}$ & 0,67 \\
\hline \multicolumn{4}{|c|}{$\begin{array}{l}\text { DVR = vivo relacionado; Cad = cadáver; } \mathrm{B}=\text { Branca; } \mathrm{M}=\text { Mulata; } \mathrm{N}=\text { Negra; } \\
{ }^{\circ} \mathrm{mg} / \mathrm{dl}\end{array}$} \\
\hline \multicolumn{4}{|c|}{ Tabela 2 - Etiologia da doença básica } \\
\hline Doença & Grupo 1 & \multicolumn{2}{|c|}{ Grupo 2} \\
\hline Glomerulonefrite crônica & 4 & \multicolumn{2}{|c|}{4} \\
\hline Nefroesclerose hipertensiva & 4 & \multicolumn{2}{|c|}{1} \\
\hline Nefropatia diabética & 0 & \multicolumn{2}{|c|}{1} \\
\hline Nefropatia do refluxo & 1 & \multicolumn{2}{|c|}{0} \\
\hline Indeterminada & 8 & \multicolumn{2}{|c|}{11} \\
\hline Total & 17 & \multicolumn{2}{|c|}{17} \\
\hline
\end{tabular}

\section{RESULTADOS}

A média da depuração de creatinina estimada no grupo 1 foi de $51,6 \pm 23,1 \mathrm{ml} / \mathrm{min}$ (inicial) e $57,2 \pm 18,8 \mathrm{ml} / \mathrm{min}$ (final), com p de 0,33 ; e, no grupo 2 , de $58,4 \pm 15,59$ (inicial) e $61,6 \pm 24,2 \mathrm{ml} / \mathrm{min}$ (final), com p de 0,49 (Tabela 3). Os dois grupos apresentaram como complicações: hipertensão arterial, dislipidemia, proteinúria, gota, anemia, infecções bacterianas e viróticas (CMV), leucopenia e outras (Tabela 4). Não foi encontrada diferença estatisticamente significativa quanto à função renal e às complicações entre os dois grupos durante o período avaliado, sendo que não ocorreram episódios de rejeição aguda, perdas de enxertos e óbitos no seguimento.

Tabela 3 - Desfecho primário da suspensão da azatioprina

\begin{tabular}{lccc}
\hline Função renal & Grupo 1 & Grupo 2 & Valor $\boldsymbol{p}$ \\
\hline Depuraçãoda creatinina inicial(CG) & $51,6 \pm 23,1$ & $58,4 \pm 15,5$ & 0,33 \\
Depuração da creatinina final(CG) & $57,2 \pm 18,8$ & $61,6 \pm 24,2$ & 0,49 \\
\hline
\end{tabular}

CG $=$ Cockroft-Gault

Tabela 4- Desfechos secundários da suspensão da azatioprina

\begin{tabular}{lccc}
\hline Desfechos & Grupo 1 & Grupo 2 & Valor p \\
\hline Hipertensão arterial & 9 & 13 & NS \\
Dislipidemia & 5 & 2 & NS \\
Proteinúria & 3 & 2 & NS \\
Gota & 1 & 2 & NS \\
Anemia & 1 & 1 & NS \\
Infecção bacteriana & 2 & 1 & NS \\
Citomegalovirose & 1 & 0 & NS \\
Leucopenia & 1 & 1 & NS \\
Outros & 8 & 4 & NS \\
\hline
\end{tabular}

\section{DISCUSSÃO}

Desde a década de 1960 a AZA, um análogo da mercaptopurina, é utilizada na imunossupressão em transplantes renais, ${ }^{9}$ sendo seu mecanismo de ação feito através da inibição da síntese das purinas com o conseqüente bloqueio da proliferação dos linfócitos T e B. É bem absorvida no tubo digestivo, apresentando nível sanguíneo de pico (C max) 1 a 2 horas após a administração oral. A metabolização dá-se no fígado pela ação da enzima xantina oxidase, sendo excretada sob forma de metabólitos inativos pelo rim.

Efeitos adversos como leucopenia, trombocitopenia, anemia, infecções, distúrbios gastrointestinais, pancreatite, hepatoxicidade, doença hepática veno-oclusiva e predisposição a neoplasias são atribuídas ao seu uso. Além disso, em casos de hiperuricemia importante, a administração conjunta de alopurinol e AZA resulta na inibição da enzima xantina oxidase pelo alopurinol, resultando em uma maior exposição a 6 -mercaptopurina, provocando 
mielotoxicidade grave. Quando é necessária a administração conjunta dessas drogas, recomenda-se reduzir a dose de AZA para 65 a 75\% da dose habitual, ou suspendê-la em alguns casos, ou, atualmente, substituí-la por outras drogas antiproliferativas, como o micofenolato ou sirolimo.

Quando a AZA foi retirada do esquema de imunossupressão nos pacientes estudados, não se dispunha ainda de informações consistentes na literatura sobre a evolução, a longo prazo, com regime terapêutico baseado em duas drogas (CsA e PRED), além da inexistência de outras drogas antiproliferativas, que pudessem substituí-la. Uma meta-análise, realizada em 1997, sugere a equivalência entre os dois regimes. ${ }^{10}$

Em nosso estudo, as principais causas para retirada da AZA da terapia imunossupressora foram a necessidade de tratamento da hiperuricemia pelo alopurinol, hepatotoxicidade, pancreatite, anemia importante e pacientes portadores de hepatite $\mathrm{B}$ ou $\mathrm{C}$.

A hepatite por AZA é caracterizada pela icterícia associada à colestase intra-hepática, com rápida regressão clínicolaboratorial, após suspensão da droga. Em pacientes transplantados renais, a hepatite por AZA parece ser facilitada ou induzida pela infecção crônica do vírus da hepatite $\mathrm{B}$ ou $\mathrm{C}$. A redução ou suspensão das doses de AZA, na ocorrência de possível hepatotoxicidade, deve ser combinada à avaliação diagnóstica e ao tratamento das doenças hepáticas virais. ${ }^{11}$

A suspensão da AZA do esquema com CsA e PRED reduz a potência da imunossupressão e, por conseqüência, seus efeitos colaterais, ${ }^{12,13}$ principalmente, a anemia e as infecções, o que não ocorreu neste estudo. A proteinúria, provavelmente decorrente da nefropatia crônica do enxerto, foi semelhante em ambos os grupos.

Concluindo, a retirada da AZA do esquema de imunossupressão com CsA e PRED em pacientes com mais de três meses de Tx não determinou complicações importantes na evolução do enxerto renal, no período de 2 anos, sendo semelhantes quando comparadas ao do esquema CsA, AZA e PRED. Entretanto, devido ao número pequeno de pacientes incluídos neste trabalho, a poucas publicações na literatura, e, ao seguimento de apenas dois anos, julgamos necessários estudos com um maior número de pacientes e uma análise mais tardia.

\section{ABSTRACT}

Introduction: Until 1997 classical immunosuppression included three drugs, namely cyclosporine, azathioprine and prednisone. However, in selected cases azathioprine was removed due to significant adverse effects. Objective: To compare the progression of renal transplant patients in which following azathioprine was removed from the immunosuppression regimen of cyclosporine, azathioprine and prednisone, to patients maintained under the triple immunosuppression regimen. Method: The study was a cohort, retrospective and observational investigation. Thirty-four similar patients submitted to first transplant were divided into two groups: azathioprine was removed in the 17patient group 1 and was maintained in the group 2, together with cyclosporine and prednisone. Results: Renal function, proteinuria, arterial hypertension, dyslipidemia, infection and other complications were similar in both groups. Conclusion: The removal of azathioprine from the initial immunosuppression regimen, which also includs cyclosporine and prednisone, in renal transplant patients with at least three months of following transplant, did not cause significant complications in the progression of the graft.

Key words: Azathioprine, Transplant, Progression, Removal and immunosuppression.

\section{REFERÊNCIAS}

1. Cecka JM, Terasaki PI. The Unos Scientific Renal Transplant Registry. In: Clinical Transplants 1992. Los Angeles: UCLA Tissue Typing Laboratory; 1993.

2. Opelz G. Effect of the maintenance immunosuppressive drug regimen on kidney drug regimen outcome. Transpl 1994; 58:443.

3. Burke JF, Pirsch JD, Ramos El et al. Long term efficacy and safety of cyclosporine in renal transplant recipients. N Engl J Med 1994; 331:358.

4. Simmom RL, Carafax DM, Fryd DS et al. New immunosuppression drug combinations for mismatch related and cadaveric renal transplantation. Transplant Proc 1986;18 (suppl 1):36.

5. Fries D, Kechrid C, Charpentier B et al. A prospective study of a triple association: cyclosporin, corticoesteroids and azathioprine in immunologically high risk renal transplantation. Transplant Proc 1985;17:1213.

6. Fries D, Hiesse C, Charpentier B et al. Triple combination of low dose cyclosporin, azathioprine and steroids in first cadaver donor renal allografts. Transplant Proc 1987; 19:1911.
7. Jones RM, Murie JA, Allen RD. Triple therapy in cadaver renal transplantation. Br J Surg 1988;75:4

8. Danovitch G. Handbook of kidney transplantation. Philadelphia: Lippincott Williams e Wilkins; 2001.

9. Opelz T. Collaborative transplant study: 10 year report. Transplant Proc 1992; $24: 2342$.

10. Kunz R, Neumayer H. Maintenance therapy with triple versus double immunosuppressive regimen in renal transplantation: a metaanalysis. Transpl 1997; 63:386.

11. Pol S, Cavalcant R et al. Azathioprine hepatitis in kidney transplant recipients: a predisposing role of chronic renal hepatitis. Transpl 1996;61(12):1774.

12. Lindholm A, Albrecht D, Karlberg I et al. A randomized trial of cyclosporine, azathioprine and prednisolone in primary cadaveric renal transplantation. Transpl $1992 ; 54: 624$.

13. Ponticelli C, Tarantino A, Montagmino G et al. A randomized trial comparing triple drug and double drug therapy in renal transplantation. Transpl 1998;45:913. 